\title{
The Prevalence of Allergic Rhinitis, its Triggers, and Associated Factors in Commonwealth of Independent States Countries (Ukraine, Kazakhstan, and Azerbaijan): Results of the CORE Study
}

\author{
Damilya Nugmanova $^{a}$ Yuriy Feshchenko ${ }^{b}$ Yelena Khegay ${ }^{a}$ Liudmila lashyna $^{b}$ \\ Olga Gyrinac Averyan Vasylyev ${ }^{d}$ Ilgar Mustafayeve Gulzar Aliyeva ${ }^{\mathrm{e}}$ \\ Marina Moibenko ${ }^{d}$ Luqman Tariq $^{d}$ Janina Makarova ${ }^{f}$ \\ aSemey State Medical University, Almaty, Kazakhstan; b National Institute of Phthisiology and Pulmonology F.G. Yanovsky \\ of NAMS, Kiev, Ukraine; 'National Medical University n.a. A.A. Bogomolets, Kiev, Ukraine; dGlaxoSmithKline, Kiev, Ukraine; \\ eScientific Research Institute of Lung Diseases, Baku, Azerbaijan; ${ }^{\mathrm{f} G l a x o S m i t h K l i n e, ~ M o s c o w, ~ R u s s i a ~}$
}

\section{Keywords}

Allergic rhinitis · Prevalence · Ukraine · Kazakhstan ·

Azerbaijan

\begin{abstract}
Background: In the Commonwealth of Independent States (CIS) countries the epidemiology of allergic rhinitis (AR) is poorly characterized. The rationale and design of the CORE (Chronic Obstructive REspiratory diseases) study have been described elsewhere. Methods: A total of 2,842 adults ( $\geq 18$ years) were recruited (964 in Kiev, Ukraine, 945 in Almaty, Kazakhstan, and 933 in Baku, Azerbaijan) between 2013 and 2015 and interviewed during household visits. Two-step cluster randomization was used for the sampling strategy. "Doctor-diagnosed AR" was considered when the respondent had previously been diagnosed with AR by a doctor, "self-reported AR symptoms" (was defined as watery runny nose during the last 12 months alone or in combination with any of the following: sneezing, nasal obstruction, nasal itching, or conjunctivitis). Results: The prevalence of doctor-diagnosed AR was $33.4,92.1$, and 82.7 per 1,000 persons, and
\end{abstract}

the prevalence of self-reported AR symptoms was 44.7, 97.4, and 85.7 per 1,000 persons, in Ukraine, Kazakhstan, and Azerbaijan, respectively. In Ukraine, the peak of AR symptoms was in May, in Kazakhstan - in May-September, and in Azerbaijan in March-May. Sneezing and nasal congestion were the most frequent symptoms. Pollen as AR trigger was reported by $71.9 \%$ respondents in Ukraine, $70.1 \%$ in Kazakhstan, and $68.8 \%$ in Azerbaijan. Only $35-56 \%$ respondents with doctor diagnosed AR have had specific investigations (skin test, analysis for immunoglobulin etc.). The percent of subjects with chronic (nonrespiratory) health condition was higher in the respondents with self-reported AR symptoms compared to rest of the respondent: 100 versus $42 \%$ in Ukraine, 100 versus $21 \%$ in Kazakhstan, and 100 versus $50 \%$ in Azerbaijan, respectively. Conclusion: In CIS countries, the prevalence of self-reported AR symptoms was slightly higher than the prevalence of doctor-diagnosed AR. Compared to countries from other continents, the prevalence of doctordiagnosed AR was similar; however, the prevalence of AR symptoms seems to be relatively lower.

(c) 2021 The Author(s)

Published by S. Karger AG, Basel karger@karger.com www.karger.com/dmj

Karger $\stackrel{\text { ' }}{=}$

BOPEN ACCESS
(C) 2021 The Author(s)

Published by S. Karger AG, Basel

This article is licensed under the Creative Commons AttributionNonCommercial-NoDerivatives 4.0 International License (CC BYNC-ND) (http://www.karger.com/Services/OpenAccessLicense) Usage and distribution for commercial purposes as well as any distribution of modified material requires written permission.
Correspondence to:

Janina Makarova, yana.j.makarova@gsk.com 


\section{Background}

Allergic rhinitis (AR) is an inflammation of the nasal mucosa triggered by allergens. The complete etiology for the development of this atopic disease is not yet understood. Several putative factors for allergic sensitization have been proposed, such as changes in lifestyle; increase in exposure to allergens, pollution, and irritants (smoke, gas, etc.); changes in diet responsible for the diminution of protective nutrient intake; decrease in infections; and stress $[1,2]$. AR is not life-threatening but can greatly affect the quality of life; the most common impact is sleep disturbances as a result of nasal symptoms, which can substantially decrease productivity [3].

It is estimated that AR currently affects up to $40 \%$ of the worldwide population, and high prevalence is being recorded in developed countries [4]. A large epidemiological study ISAAC (International Study of Asthma and Allergies in Childhood) was aimed to assess the prevalence of asth$\mathrm{ma}, \mathrm{AR}$, and atopic eczema in children and adolescents [5], though in adults standardized epidemiological data is more limited. In adult urban population beyond Europe and North America, the prevalence of AR symptoms selfreported using standardized questionnaires ranged from 5.5 to $35.5 \%$ [6-9]. The prevalence of doctor diagnosed AR in adults was 7-17\% [10]. The prevalence of AR confirmed by allergen test was $16.2-23.1 \%[11,12]$.

In post-Soviet countries, epidemiological data are limited. In Russia, an epidemiological study on adults was conducted in 2011-2012 using the GARD questionnaire [13]. The prevalence of AR-specific symptoms (running nose along with the presence of at least one of the symptoms of sneezing or nasal congestion) was $18.2 \%$, whereas previous AR diagnosis was reported by $6.5 \%$ of respondents only [13]. In a central region of Ukraine (Vinnitsa), the prevalence of AR among young adults (18-27 years old) was $7.17 \%$ in 2013-2014, and the incidence of allergic diseases in Vinnitsa increased by 3 times within last 20 years [14]. The official statistical data in post-Soviet countries typically are based on data obtained from subjects visiting doctors in the past, and therefore are 2-10 times lower than data published in the epidemiological studies [15].

To obtain more extensive epidemiological data, the CORE (Chronic Obstructive REspiratory diseases in Commonwealth of Independent States [CIS] countries) study was conducted from the first half of 2013 until the end of 2015 in Ukraine, Kazakhstan, and Azerbaijan [16]. The prevalence of COPD and bronchial asthma were described in separate articles. This manuscript is focused on the AR epidemiology derived from the study.

\section{Methods}

Overall Design, Setting, and Participants

The CORE study was aimed to evaluate the prevalence of COPD, bronchial asthma, and AR in Kiev, Ukraine; Almaty, Kazakhstan; and Baku, Azerbaijan. Adult residents of the selected cities who provided written informed consent for participation were enrolled to this multinational, cross-sectional epidemiological study. Study respondents were recruited during household visits. Beforehand the Study Executive Committee randomly selected streets for household visits in each city (country) applying 2-step stratified random cluster sampling procedure; its methodology is described previously [16] and included in Appendix 1.

The investigators (interviewers) visited households sequentially, starting with the first apartment of the first number of the house in the selected street and continuing in ascending order. Ten respondents per street were enrolled, with stratification by age: 5 respondents aged $18-39$ years old and 5 respondents aged $\geq 40$ years old from the selected street. Additional attempts were made, if a potential participant was not available during the visit, in order to minimize selection bias.

At every household, consented respondents were enrolled, if they were able to answer the study questionnaires (ATS Respiratory Symptoms Questionnaire, COPD Assessment Test [CAT], Alcohol Intake, Tobacco Smoking Questions, and Allergic Rhinitis Questionnaire) and excluded in case mental disorders and/or illiteracy (i.e., inability to read/write) limited them in completing the questionnaires. All enrolled respondents provided their sociodemographic information (gender, age, and ethnicity distribution; BMI; smoking status; and alcohol intake) and medical history (chronic medical conditions, a history of pneumonia and tuberculosis), underwent weight/height measurement and completed the study questionnaires. The study questionnaires have been described previously [16]. The Allergic Rhinitis Questionnaire was developed for the purposes of this study based on the recommendations of International Primary Care Respiratory Group (IPCRG) guidelines [17] to comply with the definition of AR recommended by Allergic Rhinitis and its Impact on Asthma (ARIA) guideline [18]. The Allergic Rhinitis Questionnaire can be found in Appendix 2.

\section{Case Definition}

Based on the study questionnaires results, 2 definitions of AR were used in this study: (1) doctor-diagnosed AR and (2) self-reported AR symptoms. Doctor-diagnosed AR was considered when the respondent reported that he/she had ever been diagnosed with AR by a doctor, that is, answered positively the question "Has a doctor ever told you that you have allergic rhinitis"? Such respondents were asked to indicate the number of AR exacerbations during the last year. Self-reported AR symptoms were defined, when the respondent reported the presence of watery runny nose (during the last 12 months) alone or in combination with any of the following: sneezing, nasal obstruction, nasal itching, or conjunctivitis in the Allergic Rhinitis Questionnaire. The Allergic Rhinitis Questionnaire can be found in Appendix 1.

\section{Statistical Analysis}

The prevalence of AR was estimated using the definitions described above, in populations with valid data, and is expressed as a number per 1,000 for each country; 95\% confidence intervals 
(CI) were calculated using the Clopper-Pearson method [19]; $\chi^{2}$ tests were used to assess differences in proportions. Binary logistic regression was used to estimate odds ratios (OR) and 95\% CI for association between $\mathrm{AR}$ and potential factors of interest: smoking (never smoked or current/past smoker), BMI ( $\geq 25$ or $<25 \mathrm{~kg} / \mathrm{m}^{2}$ ), tuberculosis (present or absent in medical history), and dusty work (reported or not reported by the respondent). Statistical significance was assumed when $p<0.050$. Statistical analysis was performed using IBM SPSS Statistics software (IBM Corp., Armonk, NY, USA) version 21.0 and R software version 3.1.2 (R Core Team, Vienna, Austria).

\section{Results}

\section{Study Sample and Demographics}

A total of 2,842 adult subjects were included in the CORE study (964 - in Ukraine, 945 - in Kazakhstan, and 933 - in Azerbaijan). The overall response rate, defined as the ratio between the number of respondents who were enrolled and the number of potentially eligible subjects, was $90.4 \%$ in Ukraine, $85.4 \%$ in Kazakhstan, and $96.9 \%$ in Azerbaijan. Women were slightly predominant: $58.2 \%$ in Ukraine; 63.2\% in Kazakhstan, and 58.3\% in Azerbaijan. The mean age was $40.7,42.5$, and 40.7 years, respectively. More details about the demographic characteristics of the respondents can be found in Appendix 3.

\section{Prevalence of $A R$}

The prevalence of doctor-diagnosed AR was 33.4 (95\% CI 23.0-46.9) per 1,000 in Ukraine, 92.1 (95\% CI 74.4112.3) per 1,000 in Kazakhstan, and 82.7 (95\% CI 65.8102.3) per 1,000 in Azerbaijan. The estimated prevalence of self-reported AR symptoms was slightly higher among all participating countries compared to doctor-diagnosed AR estimates: 44.7 (95\% CI 32.5-59.7) per 1,000 in Ukraine, 97.4 (95\% CI 79.2-118.1) per 1,000 in Kazakhstan, and 85.7 (95\% CI 68.6-105.6) per 1,000 in Azerbaijan (Fig. 1). Among the respondents with doctor-diagnosed AR, 30 (93.8\%) respondents in Ukraine, 69 (89.7\%) in Kazakhstan, and 71 (92.3\%) in Azerbaijan had at least one exacerbation during the last year.

A higher prevalence of doctor-diagnosed AR and selfreported AR symptoms was observed in the age-group $\geq 65$ years old compared to the younger age-groups in Ukraine (41.7 [95\% CI 8.7-117.0] and 84.5 [95\% CI 31.6174.9] per 1,000, respectively). However, in Kazakhstan the highest prevalence was observed in the 40-64 years old age-group (96.9 [95\% CI 70.5-129.2] and 113.5 [95\% CI 84.9-147.6] per 1,000, correspondingly) and in Azerbaijan in the 18-39 years old age-group for doctor-diag-

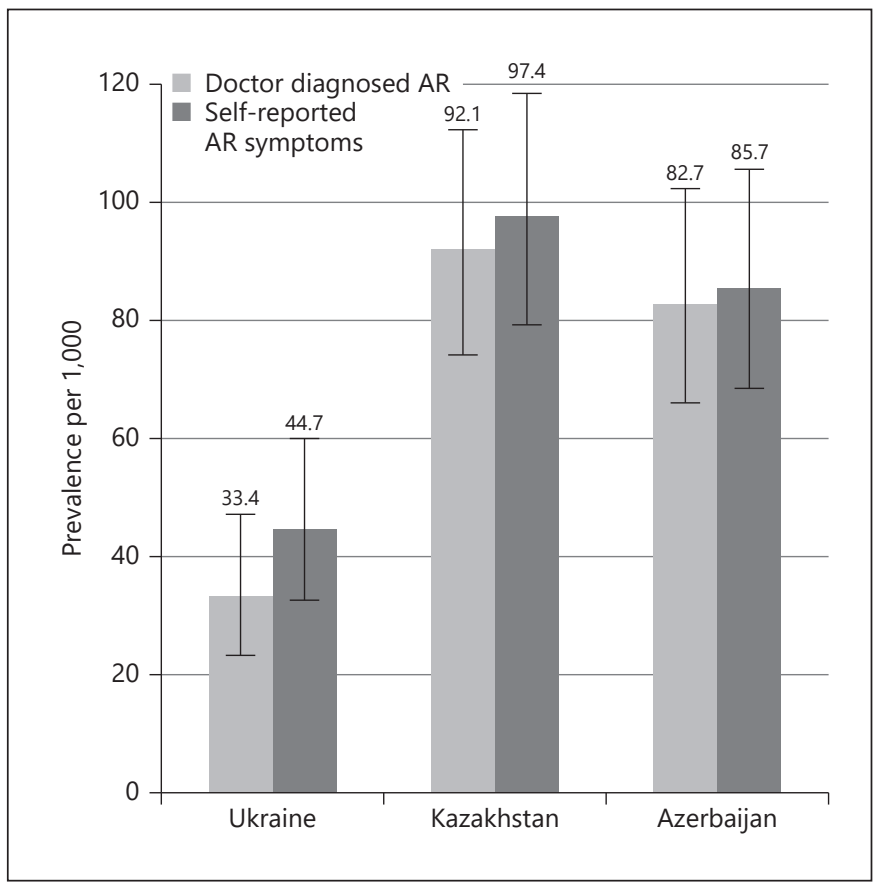

Fig. 1. Prevalence of doctor-diagnosed AR and self-reported AR symptoms (prevalence per 1,000 and 95\% CI). The prevalence was calculated per 1,000 persons and expressed with $95 \%$ CI for 2 definitions: doctor-diagnosed $A R$ : when the respondent reported that he/she had ever diagnosed with AR by a doctor while completing the study questionnaire, and self-reported AR symptoms: when the respondent reported the presence of watery runny nose (during the last 12 months) alone or in combination with any of the following: sneezing, nasal obstruction, nasal itching, or conjunctivitis in the Allergic Rhinitis Questionnaire. AR, allergic rhinitis; CI, confidence interval.

nosed AR (101.1 [95\% CI 75.2-132.1] and in the $\geq 65$ years old age-group for self-reported AR symptoms: 115.4 per 1,000 [95\% CI 43.5-234.4]) (Fig. 2).

In all 3 participating countries, $\mathrm{AR}$ was more common in women. The prevalence of doctor-diagnosed AR was 20.1 (95\% CI 8.7-39.1) per 1,000 in men versus $43.0(95 \%$ CI 27.7-63.3) per 1,000 in women in Ukraine; 71.8 (95\% CI 47.0-104.2) per 1,000 in men versus 103.9 (95\% CI 80.6-131.2) per 1,000 in women in Kazakhstan; 36.0 (95\% CI 19.8-59.7) per 1,000 in men versus 116.2 (95\% CI 90.5-146.3) per 1,000 in women in Azerbaijan. The prevalence of self-reported AR symptoms was 29.8 (95\% CI 15.5-51.4) per 1,000 in men versus 55.4 (95\% CI 37.977.7) per 1,000 in women in Ukraine; 66.1 (95\% CI $42.4-$ 97.5) per 1,000 in men versus 115.6 (95\% CI 91.0-144.0) per 1,000 in women in Kazakhstan; 72.0 (95\% CI 48.4102.4) per 1,000 in men versus 95.6 (95\% CI 72.2-123.5) per 1,000 in women in Azerbaijan (Fig. 3). 


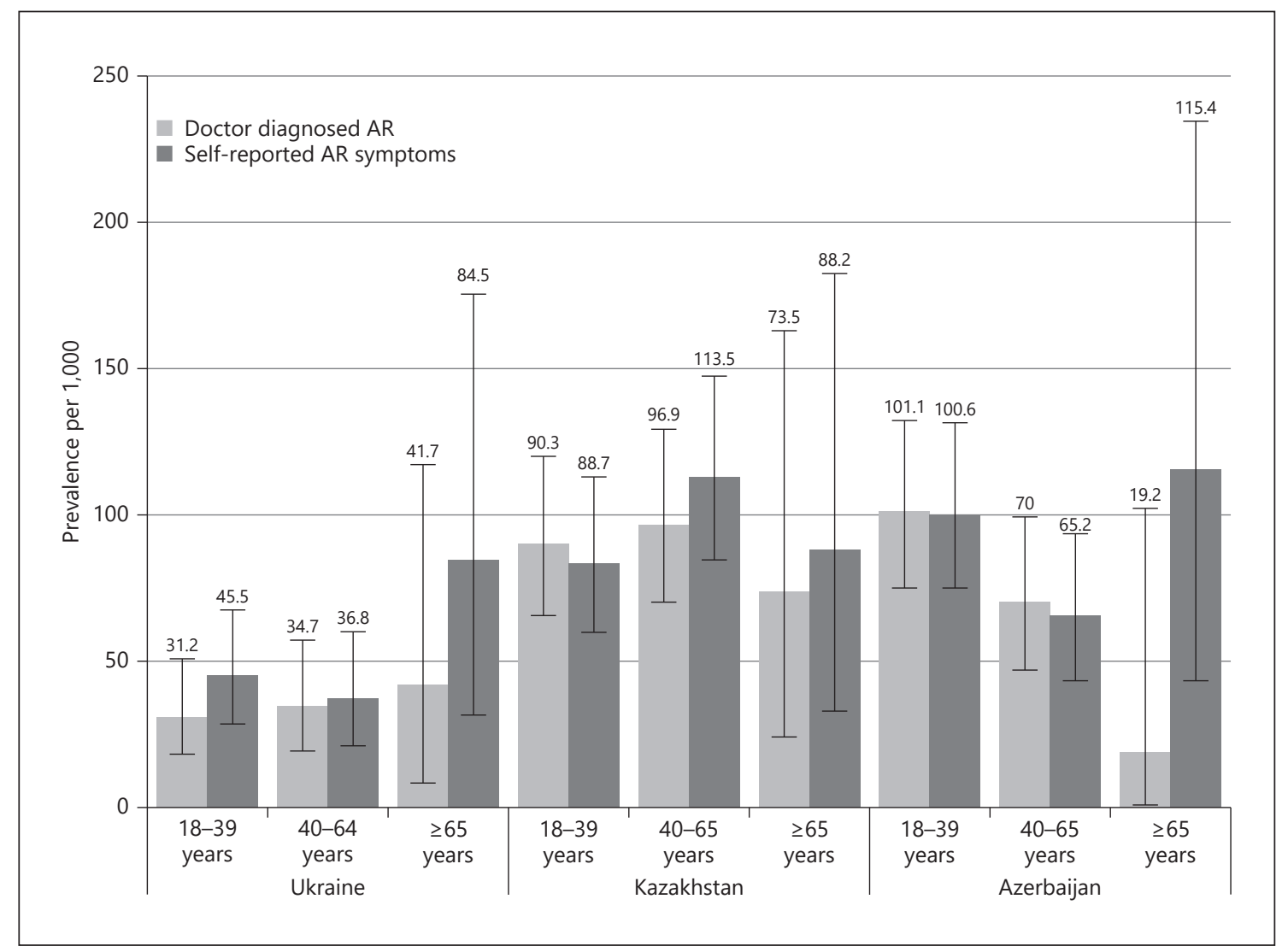

Fig. 2. Prevalence of doctor-diagnosed AR and self-reported $A R$ symptoms stratified by age (prevalence per 1,000 and 95\% CI). The prevalence was calculated per 1,000 persons and expressed with $95 \%$ CI in 3 age-groups: $18-39,40-64$, and $\geq 65$ years old, for doctor-diagnosed AR: when the respondent reported that he/she had ever diagnosed with AR by a doctor while completing the study

The ethnicity-specific prevalence of AR was estimated only in Kazakhstan because 99.7\% respondents in Ukraine and $100 \%$ in Azerbaijan were Caucasians (in Kazakhstan, Asians proportion was 62.8\%). Generally, in Kazakhstan, the prevalence of AR in Asians was higher than in Caucasians, both for doctor diagnosed AR (96.1 [95\% CI 73.6$122.8]$ per 1,000 [57/593 persons] in Asians vs. 83.1 [95\% CI 56.4-117.2] per 1,000 [29/349 persons] in Caucasians) and for self-reported AR symptoms (109.6 [95\% CI 85.6137.6] per 1,000 [65/593 persons] in Asians vs. 77.4 [95\% CI 51.6-110.6] per 1,000 [27/349 persons] in Caucasians).

\section{AR Description in the Allergic Rhinitis Questionnaire}

Table 1 reports the characteristics in the Allergic Rhinitis Questionnaire of respondents who had doctor-diagnosed AR (32 in Ukraine, 87 in Kazakhstan, and 77 in Azerbaijan). In Ukraine, the peak of AR symptoms was in questionnaire, and self-reported AR symptoms: when the respondent reported the presence of watery runny nose (during the last 12 months) alone or in combination with any of the following: sneezing, nasal obstruction, nasal itching, or conjunctivitis in the Allergic Rhinitis Questionnaire. AR, allergic rhinitis; CI, confidence interval.

May (69\% respondents); in Kazakhstan, from May to September ( $>50 \%$ respondents); and in Azerbaijan in March-May ( $>70 \%$ respondents). Sneezing was the most frequent symptom (75\% of respondents in Ukraine, $92 \%$ in Kazakhstan, and $85.7 \%$ in Azerbaijan). Pollen, a common AR trigger, was reported by $71.9 \%$ respondents in Ukraine, 70.1\% in Kazakhstan, and 68.8\% in Azerbaijan.

Association between Smoking, History of Tuberculosis, Dusty Work, Overweight/Obesity, and AR

The relationship between the presence of self-reported AR symptoms and smoking status (current/past smoker), BMI (BMI $\geq 25 \mathrm{~kg} / \mathrm{m}^{2}$ ), tuberculosis (ever diagnosed), and dusty work was investigated and statistical significance was found between AR symptoms and overweight/obesity in Ukraine (OR 0.305 [CI 0.145-0.643], $p=0.001$ ) and Azerbaijan (OR 0.578 [CI 0.364-0.919], $p=0.019$ ) (Fig. 4). 


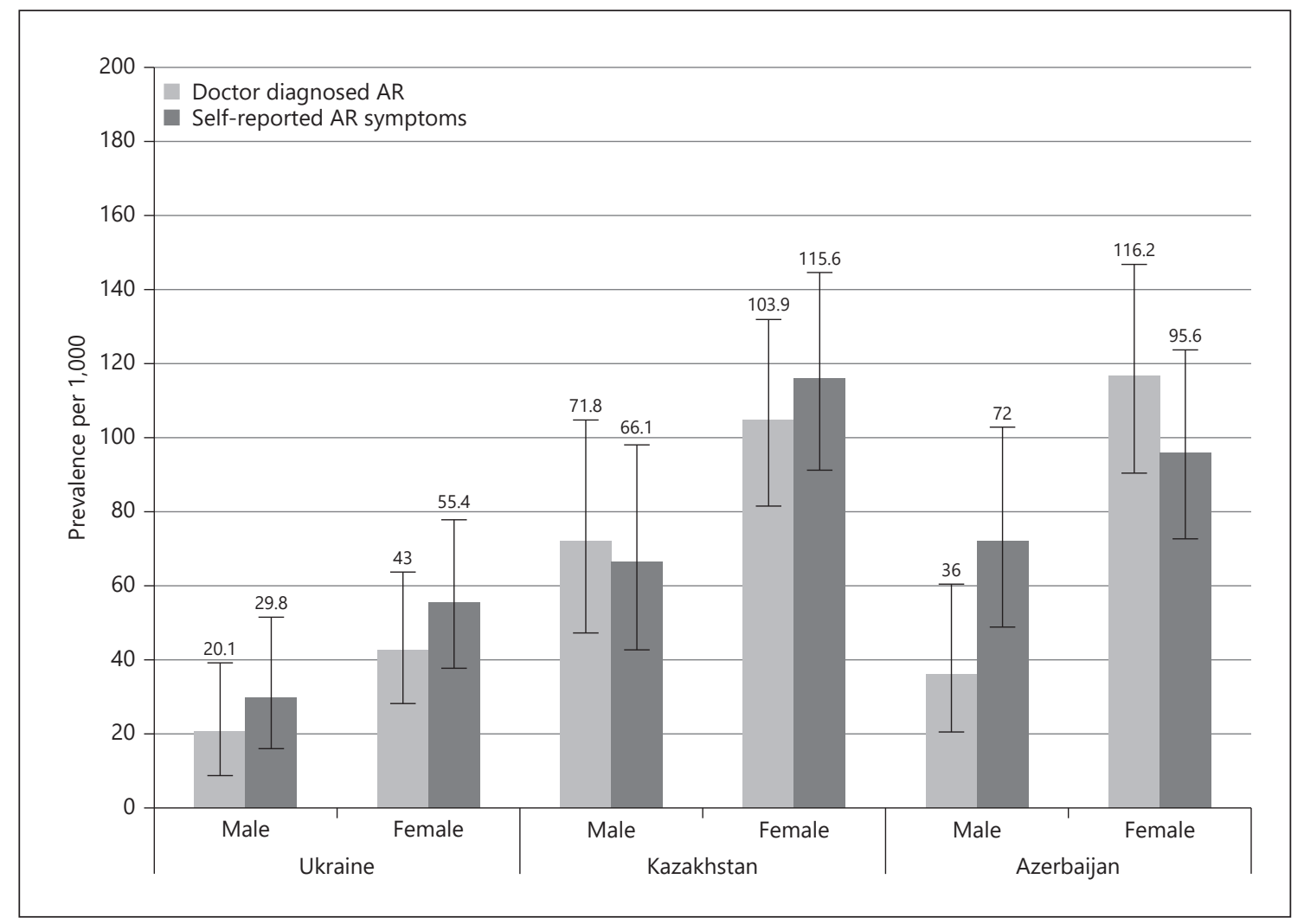

Fig. 3. Prevalence of doctor-diagnosed $A R$ and self-reported AR symptoms stratified by gender (prevalence per 1,000 and $95 \%$ $\mathrm{CI})$. The prevalence was calculated per 1,000 persons and expressed with 95\% CI, among men and women, for doctor-diagnosed AR: when the respondent reported that he/she had ever diagnosed with AR by a doctor while completing the study ques-

\section{Comorbidities}

In all participating countries, the percent of subjects that reported suffering from a chronic health condition was significantly higher in the AR population compared to the non-AR population: 100 versus $42 \%$ in Ukraine, 100 versus $21 \%$ in Kazakhstan, and 100 versus $50 \%$ in Azerbaijan, respectively (Table 2). In Ukraine, hypertension and cardiovascular disease were more frequently observed in the AR population compared to the non-AR population; however, this difference was not shown to be significant. In Kazakhstan, hypertension, abnormal blood lipids, and a history of pneumonia were more frequent in the respondents with "self-reported AR symptoms" than in the non-AR population. Out of these 3 comorbidities, history of pneumonia was shown to be significantly more frequent in the AR versus the non-AR population $(p<$ 0.001 ); for the other 2, this was not the case. In Azerbaijan, hypertension and a history of pneumonia were more

Allergic Rhinitis Prevalence in CIS Countries tionnaire, and self-reported AR symptoms: when the respondent reported the presence of watery runny nose (during the last 12 months) alone or in combination with any of the following: sneezing, nasal obstruction, nasal itching, or conjunctivitis in the Allergic Rhinitis Questionnaire. AR, allergic rhinitis; CI, confidence interval.

frequently observed in the AR population compared to the non-AR population; however, this difference was not shown to be significant.

\section{Discussion}

The CORE study showed that the prevalence of previous diagnosis of AR (doctor-diagnosed AR) was 33.4 per 1,000 (Ukraine), 92.1 per 1,000 (Kazakhstan), and 82.7 per 1,000 (Azerbaijan) and the prevalence of self-reported AR symptoms was $44.7,97.4$, and 85.7 per 1,000 persons respectively. The prevalence of AR by age-groups showed heterogeneity (higher prevalence of doctor-diagnosed AR was observed in the age-group $\geq 65$ years old in Ukraine, 40-64 in Kazakhstan, and 18-39 in Azerbaijan; and for the self-reported AR symptoms, the highest prevalence was seen in $\geq 65$ years in Ukraine and Azerbaijan and in 40-64 
Table 1. Respondents' interview results in the Allergic Rhinitis Questionnaire (AR anamnesis)

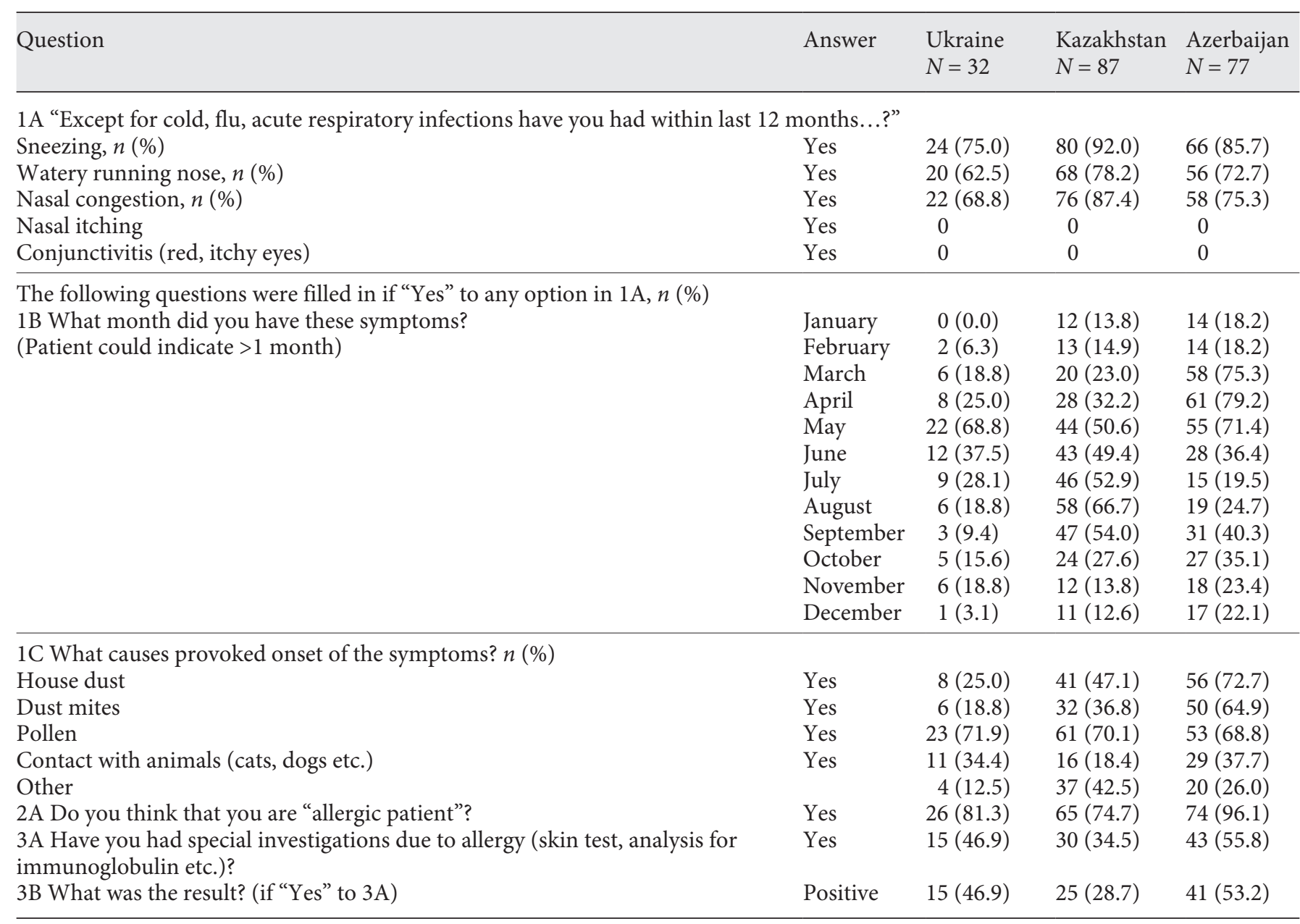

AR, allergic rhinitis.

in Kazakhstan). The observed findings are not clear. It is assumed that the prevalence of AR decreases with age due to alterations in immune function [20]; however, some studies show that it appears to be rising in elderly or is similar to estimates observed at middle age [21-23]. A large discrepancy was found in the $\geq 65$ years age-group between the prevalence of doctor-diagnosed AR and selfreported AR symptoms (the latter was higher), especially in Ukraine and Azerbaijan. This may reflect a case of potentially poor diagnostics as the symptoms of AR might be ignored or wrongly described as respiratory infections [21]; at the same time, elderly may be prone to reporting symptoms more frequently than younger adults.

In Kazakhstan, a trend toward higher prevalence estimates of AR in Asians compared to Caucasians was observed. This discrepancy might be due to differences in national features or it might merely be a case of random observation; this warrants further investigation.

In Kazakhstan and Azerbaijan, collected prevalence data is reflecting similarities with other available sources (according to ARIA, at least 10\% of the population suffers from AR). In Ukraine, it is lower in comparison with 2 other countries but higher than the current official statistics; AR prevalence is less than $1 \%$ (based on documented morbidity at healthcare system level). Potential reasons can be $\mathrm{AR}$ underdiagnosis and insufficient attention to the problem from family doctors due to local specifics of healthcare system. The usual patient's behavior is a self-treatment with following later visits to doctors only in severe cases. These lower expression of symptoms and patient behavior with cultural differences might explain lower awareness of symptoms and thus lower case reporting during the study. 


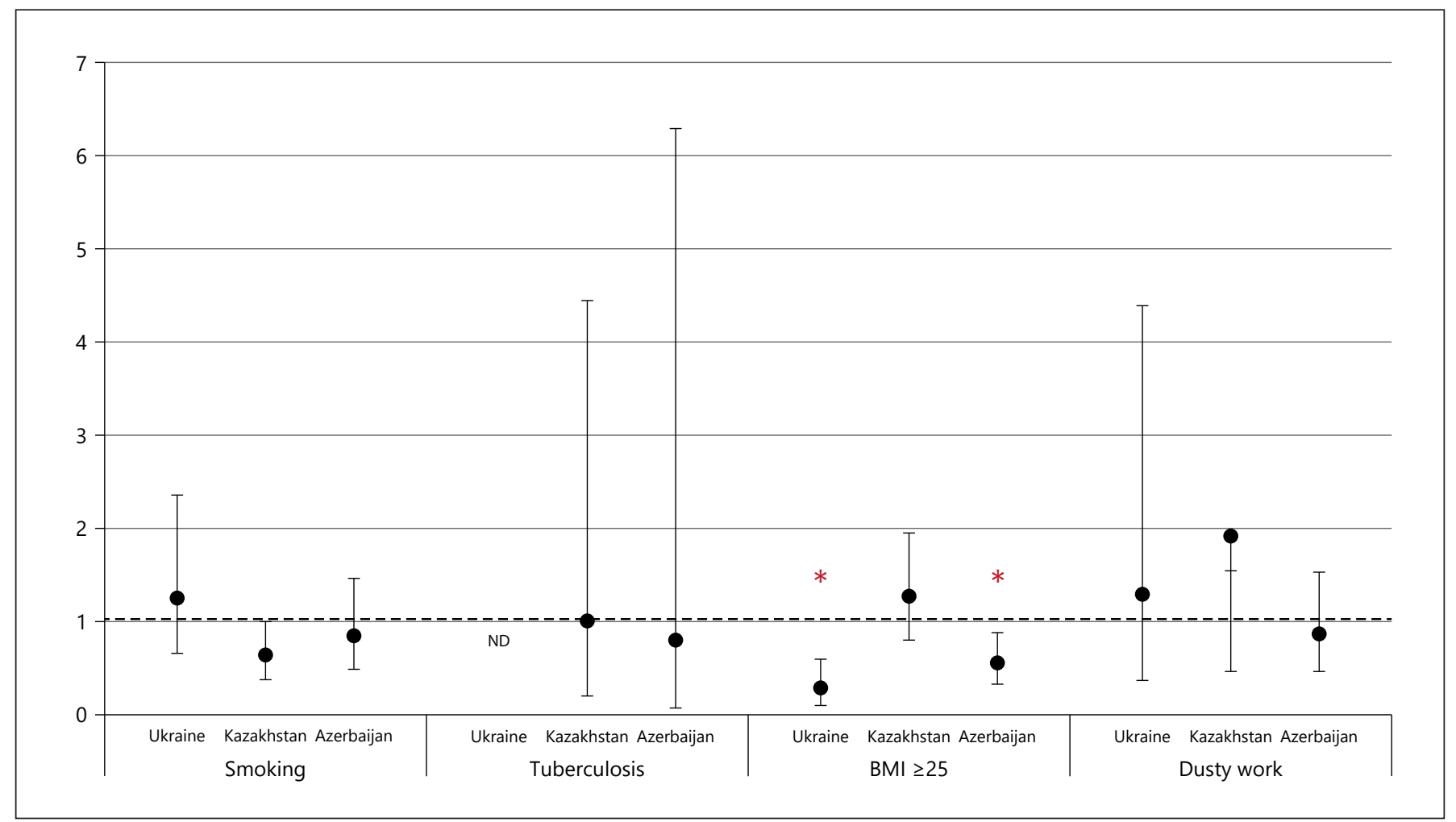

Fig. 4. Association between smoking, history of tuberculosis, dusty work, overweight/obesity, and self-reported AR symptoms. OR and $95 \%$ CI for OR are presented for each potential factor of interest. Asterisk $(*)$ denotes as statistically significant association between factor and self-reported AR symptoms $(p<0.05)$. nd, not determined; $\mathrm{AR}$, allergic rhinitis; OR, Odds ratios; CI, confidence interval.

Table 2. Comorbidities in AR and non-AR population

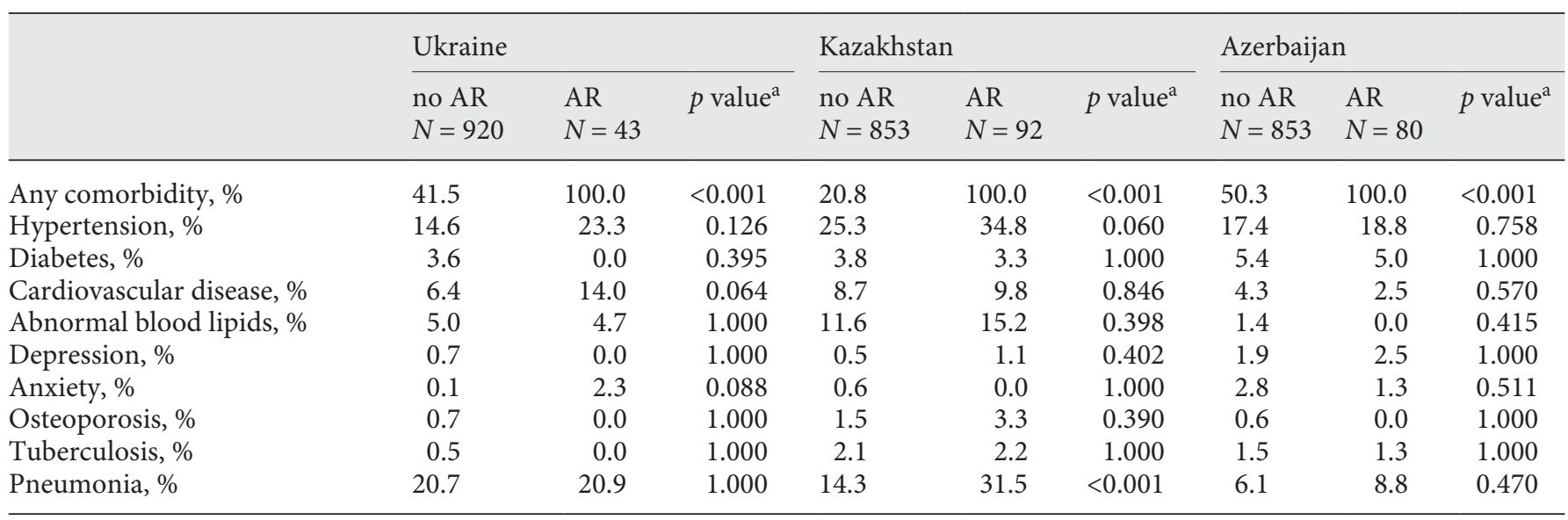

AR population: respondents who reported AR symptoms in the Allergic Rhinitis Questionnaire. Non-AR population: respondents who did not report AR symptoms in the Allergic Rhinitis Questionnaire. AR, allergic rhinitis. ${ }^{a}$ Two-sided Pearson $\chi^{2}$ test for a comparison between $\mathrm{AR}$ and non-AR populations. 
The study was not aimed to compare AR prevalence between the countries and was not powered to estimate any statistical significance between countries or any subgroups.

\section{Comparison with Published Literature}

The prevalence of doctor-diagnosed $\mathrm{AR}$ in present study (33.4 per 1,000, i.e., $3.3 \%$ in Ukraine; 92.1 per 1,000, i.e., $9.2 \%$ in Kazakhstan; and 82.7 per 1,000 , i.e., $8.3 \%$ in Azerbaijan) was similar to that obtained in Russia (6.5\%) [13] and some other studies in the world (7\% in Latin America and 9\% in Asia-Pacific region) [10]. At the same time, the prevalence of self-reported AR symptoms in present study (4.5\% in Ukraine, 9.7\% in Kazakhstan, and 8.6\% in Azerbaijan) was similar to that reported in Singapore (5.5\%) [10] and Russian polluted city Nikel (5.6\%) [10] but lower than in most other studies [6-10], including Russian GARD study [13] (18.2\%).

Lower prevalence of self-reported AR symptoms compared to many other studies may be associated with several factors. Studies could be performed in different seasons (taking into account the seasonality of AR). Subjectivity of AR symptoms and therefore methodological issues (various questionnaires used to identify AR patients, such as the ISAAC study questionnaire, the ECRHS (European Community Respiratory Health Survey) questionnaire, the Middleton diary symptom questionnaire or questionnaires standardized to local/national levels [6]) may contribute the observed differences. In this study, we evaluated the presence of AR symptoms (sneezing, watery running nose, nasal congestion, nasal itching, and conjunctivitis) during last 12 months. These questions are recommended by the ARIA guideline [16] and are comparable with questions included in the ECRHS questionnaire [24].

Another point could be related to cultural peculiarities (how people respond to questions around AR symptoms); for example, people could have insufficient knowledge about $\mathrm{AR}$ and therefore could misinterpret $\mathrm{AR}$ symptoms as cold. Possible differences from the Russian study [13] could be clarified since the period of evaluation of the symptoms in that study was not limited to a certain time period, while in our study the AR symptoms were evaluated only within the last 12 months.

\section{AR Triggers}

The study provided data on the most typical triggers of AR in the studied countries (cities). Pollen, a common trigger of AR symptoms, was reported by $69-72 \%$ respondents, but other allergens (contact with animals) also substantially contribute to AR triggers in 3 countries. Dust mites (indoor allergen) was reported by about $50 \%$ re- spondents with AR in Ukraine and much more in other 2 countries. These data are in line with other studies; the most widely spread allergens are pollen (in Australia, the Middle East countries, Southern Africa, and Turkey) and dust mites (in Asia-Pacific region) [6]. In large cities, more time is being spent indoors with increased dampness and poor ventilation caused by tight insulation of modern homes leading to increased exposure to allergens, polysensitization, and cross-reactivity among the antigens [6]. It should be noted that $13-43 \%$ of our respondents reported that their AR was provoked by other allergens which means that AR triggers could be insufficiently identified in this study and can be a subject for future research.

Another important finding from the Allergic Rhinitis Questionnaire is that almost all respondents who reported AR symptoms think that they are "allergic patient" $(>70 \%)$, but only about half of them had undergone specific investigations. This fact sums up the overall lack of knowledge about AR among population and the habit to treat the disease over the counter not consulting a physician.

\section{Comorbidities}

The results of comorbidities analysis should be interpreted with caution, taking into account quite small size of the subgroups included in the analysis. It was shown previously that people with AR are at greater risk of suffering from lower and upper airway conditions, such as asthma, sinusitis, otitis media, nasal polyposis, and other respiratory diseases $[12,25,26]$. Our study evaluated the rate of other medical conditions (cardiovascular diseases, diabetes, depression, osteoporosis etc.); no statistical differences $(p>0.05)$ were found between respondents with and without self-reported AR symptoms in the rate of these comorbidities. Higher rate of a history of pneumonia in the respondents with self-reported AR symptoms versus the respondents without them was obtained in Kazakhstan. The overall rate of some diseases could be underestimated in this study because persons who had contraindication(s) to spirometry were not enrolled in the study (spirometry was used for COPD diagnosis as part of the CORE study). Contraindications for spirometry in this study included myocardial infarction, ascending aortic aneurysm, pulmonary embolism, and angina [27].

Despite the fact that allergic conjunctivitis is often observed as a common symptom of $A R$, no respondents reported ocular symptoms. A potential reason for this could be that Allergic Rhinitis Questionnaire did not contain the explanation that ocular symptoms can be related to the rhinitis condition. Responders might therefore have consid-
88

Dubai Med J 2021;4:81-92 DOI: $10.1159 / 000514318$
Nugmanova et al. 
ered these ocular symptoms as a separate condition while another reason could be the mild intensity of conjunctivitis compared to the other (nasal) AR symptoms; therefore, the respondents might not recall it while responding to the questionnaire. The third reason could be that ocular symptoms are really less prevalent than the nasal ones, which could additionally impact such underreporting.

\section{Association of $A R$ and Other Factors}

As for other allergic diseases, factors known to be related with development or worsening of AR include both a genetic predisposition and environmental exposure [2, 3]. This study was not aimed to assess specific risk factors of AR, but the role of some environmental factors (smoking, dusty work) was evaluated, and for these factors, there was no significant association with self-reported AR symptoms. For comparison, in a recent review on the association of AR and smoking [28] the authors observed very modest associations between passive smoking (and not active smoking) and AR among adults.

The investigation of the role of tuberculosis was interesting, taking into account the "hygiene hypotheses" first formulated by Strachan DP [29]. According to this hypothesis, the decreasing incidence of infections may be at the origin of the increasing incidence of both autoimmune and allergic diseases, and there are some data that exposure to Mycobacterium tuberculosis may reduce the risk of developing asthma [30]. Several studies demonstrated that pulmonary tuberculosis in anamnesis may decrease the incidence of atopy, particularly AR symptoms [31, 32]. However, there is no proven causal link between infections and immune disorders [33]. Our study also did not find any association between tuberculosis in medical history and self-reported AR symptoms.

A finding for the reverse association between self-reported AR symptoms and overweight/obesity was found in Ukraine and Azerbaijan. The reason for such results is unclear; the literature data on the association between AR and obesity are inconsistent. In 2 recent large national studies, there was no significant association between obesity and AR [34, 35]; in some studies it is supposed that obesity in childhood or adolescence may increase the risk of allergy [36-38]. A negative correlation between overweight/obesity and AR prevalence in adults which support our findings was found in one study in Poland [39] and one in Japan [40]; in both studies, this result was seen in the age-group 20-44 years old. Further research is needed to assess potential relationship of AR and overweight/obesity.

Allergic Rhinitis Prevalence in CIS

Countries

\section{Strengths and Limitations}

The strengths of the study include a large sample size together with consistent methodology across all countries, providing a standardized measure of prevalence. Selection failure rate (proportion of respondents who were potentially eligible but refused to participate) did not exceed $10 \%$. Standardized definitions of AR were used to evaluate 2 prevalence values and match them with published data (AR diagnosed previously by a doctor and AR symptoms subjectively assessed by a respondent). This study could facilitate the recognition of AR in CIS countries and will allow preparation of educational interventions to optimize management of patients with AR.

We acknowledge that the current study has several limitations. Random selection of streets and participants cannot be totally ensured; however, the methodology of population selection was carefully prepared and such risk is minimal. The relatively small number of AR patients can limit the power for specific types of within-city analysis, such as detailed subgroup analyses. Subjective factor in reporting of AR symptoms by a respondent can lead to both under and over diagnosis of AR.

Generalizability of the study results is limited because the study was performed in major cities, but healthcare provision and accessibility to medical care may vary widely across the country, especially in rural area compared to urban agglomerations. The most apparent examples of differences between cities and rural areas may be dusty work exposure and tuberculosis (in anamnesis), which prevalence depends on social factors such as home conditions. Evaluation of risk factors for respiratory diseases was not the aim of this study; therefore, we did not evaluate such urban factors as exposure to fossil fuel and traffic-related pollutants and only crude associations between smoking, history of tuberculosis, dusty work, overweight/obesity, and AR symptoms are presented (no potential confounders included in the analysis). Multiple participants may have been recruited from a single household and they could have similarities in genes and/or environmental factors potentially influencing the study findings. On the other hand, it increases the reliability of the study findings on prevalence because it was required to be exhaustive in ensuring all participants at risk of a certain disease are included in the study.

The diagnostics of seasonal and perennial AR was not made, which was considered unnecessary, taking into account that AR treatment depends on the symptoms intensity and duration, not on AR trigger. Besides, a study participant could have the overlap of these AR forms. The seasonality of AR symptoms (the peak of AR symptoms was in 
the period from March to September) may indirectly reflect higher prevalence of seasonal AR in this study.

Next to allergic reasons, rhinitis may also have nonallergic origin (environmental or occupational irritants, weather changes, chronic infections, foods and beverages, medications, hormones etc.). In this study, the Allergic Rhinitis Questionnaire allowed excluding the most frequent nonallergic reasons (flu, cold); however, nonallergic reasons for rhinitis could not be fully excluded.

As in any epidemiological study, some data collected from respondents' interview could be missing. However, the proportion of patients with missing data for the prevalence data was only $0-1 \%$.

Finally, respondents could have greater probability to report about allergy-specific investigations, if their results were positive, which could be reporting bias. Selection bias can be related to eligibility criteria (subjects with contraindication(s) to spirometry were not enrolled). And, respondents with diagnosed AR might have undergone more diagnostic tests than people without any diseases that could be diagnostic bias.

\section{Conclusions}

In all 3 CIS countries examined in this study, the prevalence of self-reported AR symptoms was slightly higher compared to the prevalence of doctor-diagnosed AR. Data collected in this study are re-assuring as it confirms that the self-reported prevalence estimates for AR are close to the prevalence estimates obtained based on the previous diagnosis. The prevalence of doctor-diagnosed AR was similar to countries from other continents of the world; however, the prevalence of AR symptoms seems to be relatively lower.

\section{Acknowledgements}

We thank all investigators for their contribution to the study, allowing the first clinical epidemiology research to happen with a high level of integrity, and the contract research organization, Synergy Research Group, which was funded by GSK and oversaw the study organization and conduct.

\section{Statement of Ethics}

The study was reviewed and approved by an Independent Ethics Committee in Kazakhstan (Central Commission for Ethics at the Ministry of Health of the Republic of Kazakhstan) and by Local Ethics Committees in Kazakhstan, Azerbaijan, and Ukraine (Eth- ics Committee at Semey State Medical University, Almaty, Kazakhstan; Ethics Committee at Scientific Research Institute of Lung Diseases in Baku, Azerbaijan; Commission for Ethics at National Institute of Phthisiology and Pulmonology F.G. Yanovsky of NAMS, Kiev, Ukraine; and Commission for Ethics at Center for Primary Health Care \#2 of Shevchenko District, Kiev, Ukraine), according to the local legal requirements. Written informed consent was obtained from each participant before any procedures or data collection related to the study.

\section{Conflict of Interest Statement}

The study was sponsored by GlaxoSmithKline (GSK) marketing a number of treatments for COPD, allergic rhinitis, and asthma. D.N., Y.F., Y.K., L.I., O.G., G.A., and I.M. report grants from GlaxoSmithKline during the conduct of the study; personal fees from GlaxoSmithKline outside the submitted work. M.M. and J.M. are employees of GlaxoSmithKline. A.V. and L.T. are GSK employees and shareholder.

\section{Funding Sources}

Funding for this study was provided by GSK (GSK study number: RES116757 and GSK study acronym: CORE). Authors were in full editorial control of publication target journal, content, and conclusions and accepted full responsibility for final approval of a manuscript describing this GSK-sponsored research. The sponsor did not place any restrictions on access to the data or on the statements made in the manuscript.

\section{Author Contributions}

All listed authors meet the criteria for authorship set forth by the International Committee for Medical Journal Editors. Y.F., L.I., D.N., and A.V. provided support in the study concept and protocol development. National Institute of Phthisiology and Pulmonology F.G. Yanovsky National Academy of Medical Sciences of Ukraine (NIPP), Kiev, Ukraine, and Semey State Medical University, Almaty, Kazakhstan, provided advisory support to the study. Editorial support in the form of draft outline, editorial suggestions to draft versions of this paper, collating author comments, assembling tables and figures, referencing, and copyediting was provided by Julia She at Synergy Research Group and was funded by GSK. All authors were actively involved in study design, acquisition of data, analysis, and interpretation of the study data. Authors participated in critical revisions of the manuscript and have approved the article for publication. The authors contributed to the manuscript review, applying their clinical, epidemiology, and study design expertise and take responsibility for the integrity of the data and the accuracy of the data analysis.

\section{Availability of Data and Material}

The datasets used and/or analyzed during the current study are available from the corresponding author on reasonable request.
Nugmanova et al. 


\section{Appendix 1}

"Stratified random cluster sampling procedure" contains a description of methodology for stratified random cluster sampling procedure used in this study.

\section{Appendix 2}

“Allergic Rhinitis Questionnaire" contains a copy of Allergic Rhinitis Questionnaire used in this study.

\section{Appendix 3}

"Demographic characteristics of the respondents in the CORE study" contains tabular data on distribution of the respondents by their demographic data, BMI, smoking, alcohol intake, and dusty work.

Appendices 1-3 can be accessed online at www. karger.com/doi/10.1159/000514318.

\section{References}

1 Bousquet J, Van Cauwenberge P, Khaltaev N; Aria Workshop Group; World Health Organization. Allergic rhinitis and its impact on asthma. J Allergy Clin Immunol. 2001 Nov; 108(5 Suppl):S147-334.

2 Wang DY. Risk factors of allergic rhinitis: genetic or environmental? Ther Clin Risk Manag. 2005 Jun;1(2):115-23.

3 Meltzer EO, Gross GN, Katial R, Storms WW. Allergic rhinitis substantially impacts patient quality of life: findings from the nasal allergy survey assessing limitations. J Fam Pract. 2012 Feb;61(2 Suppl):S5-10.

4 Izquierdo-Domínguez A, Valero AL, Mullol J. Comparative analysis of allergic rhinitis in children and adults. Curr Allergy Asthma Rep. 2013 Apr;13(2):142-51.

5 Worldwide variation in prevalence of symptoms of asthma, allergic rhinoconjunctivitis, and atopic eczema: ISAAC. The International Study of Asthma and Allergies in Childhood (ISAAC) Steering Committee. Lancet. 1998 Apr 25;351(9111):1225-32.

6 Katelaris CH, Lee BW, Potter PC, Maspero JF, Cingi C, Lopatin A, et al. Prevalence and diversity of allergic rhinitis in regions of the world beyond Europe and North America. Clin Exp Allergy. 2011;1-22.

7 De Marco R, Cappa V, Accordini S, Rava M, Antonicelli L, Bortolami O, et al. Trends in the prevalence of asthma and allergic rhinitis in Italy between 1991 and 2010. Eur Respir J. 2012 Apr;39(4):883-92.

8 Eriksson J, Ekerljung L, Rönmark E, Dahlén B, Ahlstedt S, Dahlén SE, et al. Update of prevalence of self-reported allergic rhinitis and chronic nasal symptoms among adults in Sweden. Clin Respir J. 2012 Jul;6(3):159-68.

9 Canuel M, Lebel G. Epidemiology of allergic rhinitis in Quebec: from a 2008 populationbased survey. Chronic Dis Inj Can. 2014 Jul; 34(2-3):163-8

10 Meltzer EO, Blaiss MS, Naclerio RM, Stoloff SW, Derebery MJ, Nelson HS, et al. Burden of allergic rhinitis: allergies in America, Latin America, and Asia-Pacific adult surveys. Allergy Asthma Proc. 2012 Sep-Oct;33(33 Suppl 1):S113-41.
11 Grønhøj Larsen C, Gyldenløve M, Linneberg A. Allergic rhinitis is often undiagnosed and untreated: results from a general population study of Danish adults. Clin Respir J. 2013 Oct;7(4):354-8.

12 Rhee CS, Wee JH, Ahn JC, Lee WH, Tan KL, Ahn S, et al. Prevalence, risk factors and comorbidities of allergic rhinitis in South Korea: the Fifth Korea National Health and Nutrition Examination Survey. Am J Rhinol Allergy. 2014 Mar-Apr;28(2):e107-14.

13 Chuchalin AG, Khaltaev N, Antonov NS, Galkin DV, Manakov LG, Antonini P, et al. Chronic respiratory diseases and risk factors in 12 regions of the Russian Federation. Int $J$ Chron Obstruct Pulmon Dis. 2014 Sep 12;9: 963-74.

14 Hatska DO, Korytska IV. Allergic disease among children and teenagers in Vinnitsa region: time trends of the incidence (1st stage of clinical and epidemiologic study). Asthma Allergy. 2015;1:17-22.

15 Akpeisova RB. A contemporary view of allergic rhinitis. Izvestiya NAN RK. Biol Ser. 2008; 2:16-21.

16 Feshchenko Y, Iashyna L, Nugmanova D, Gyrina $\mathrm{O}$, Polyanskaya $\mathrm{M}$, Markov $\mathrm{A}$, et al. Chronic obstructive pulmonary disease, bronchial asthma and allergic rhinitis in the adult population within the Commonwealth of Independent States: rationale and design of the CORE study. BMC Pulm Med. 2017; 17(1):131.

17 Levy ML, Fletcher M, Price DB, Hausen T, Halbert RJ, Yawn BP. International primary care respiratory group (IPCRG) guidelines: diagnosis of respiratory diseases in primary care. Prim Care Respir J. 2006;15(1):20-34.

18 Allergic Rhinitis and its Impact on Asthma (ARIA). Management of allergic rhinitis and impact on asthma: pocket guide. In: Based on the 2007 ARIA workshop report and the IPAG handbook; 2007. Available from: http: //www.whiar.org

19 Clopper CJ, Pearson ES. The use of confidence or fiducial limits illustrated in the case of the binomial. Biometrika. 1934;26(4):40413.
20 Pinto JM, Jeswani S. Rhinitis in the geriatric population. Allergy Asthma Clin Immunol. 2010 May 13;6(1):10.

21 Milgrom $\mathrm{H}$, Huang $\mathrm{H}$. Allergic disorders at a venerable age: a mini-review. Gerontology. 2014;60(2):99-107.

22 Cazzoletti L, Ferrari M, Olivieri M, Verlato G, Antonicelli L, Bono R, et al. The gender, age and risk factor distribution differs in self-reported allergic and non-allergic rhinitis: a cross-sectional population-based study. Allergy Asthma Clin Immunol. 2015 Dec 4;11: 36.

23 Kim TB, Kim YK, Chang YS, Kim SH, Hong SC, Jee YK, et al. Association between sensitization to outdoor spider mites and clinical manifestations of asthma and rhinitis in the general population of adults. J Korean Med Sci. 2006 Apr;21(2):247-52.

24 The European Community Respiratory Health Survey II. Main Questionnaire. Available at: http://www.ecrhs.org/quests/ecrhsiimainquestionnaire.pdf.

25 Spector SL. Overview of comorbid associations of allergic rhinitis. J Allergy Clin Immunol. 1997 Feb;99(2):S773-80.

26 Hadley JA, Derebery MJ, Marple BF. Comorbidities and allergic rhinitis: not just a runny nose. J Fam Pract. 2012 Feb;61(2 Suppl):S11-

27 Cooper BG. An update on contraindications for lung function testing. Thorax. 2011 Aug; 66(8):714-23.

28 Saulyte J, Regueira C, Montes-Martínez A, Khudyakov P, Takkouche B. Active or passive exposure to tobacco smoking and allergic rhinitis, allergic dermatitis, and food allergy in adults and children: a systematic review and meta-analysis. PLoS Med. 2014 Mar 11;11(3): e1001611.

29 Strachan DP. Hay fever, hygiene, and household size. BMJ. 1989;299(6710):1259-60.

30 von Mutius E, Pearce N, Beasley R, Cheng S, von Ehrenstein O, Björkstén B, et al. International patterns of tuberculosis and the prevalence of symptoms of asthma, rhinitis, and eczema. Thorax. 2000 Jun;55(6):44953. 
31 Lin CT, Gopala K, Manuel AM. The impact of pulmonary tuberculosis treatment on the prevalence of allergic rhinitis. Ear Nose Throat J. 2013 Aug;92(8):358-99.

32 Obihara CC, Beyers N, Gie RP, Potter PC, Marais BJ, Lombard CJ, et al. Inverse association between Mycobacterium tuberculosis infection and atopic rhinitis in children. Allergy. 2005 Sep;60(9):1121-5.

33 Okada H, Kuhn C, Feillet H, Bach JF. The "hygiene hypothesis" for autoimmune and allergic diseases: an update. Clin Exp Immunol. 2010 Apr;160(1):1-9.

34 Ahn JC, Kim JW, Lee CH, Rhee CS. Prevalence and risk factors of chronic rhinosinusitus, allergic rhinitis, and nasal septal deviation: results of the Korean National Health and Nutrition Survey 2008-2012. JAMA Otolaryngol Head Neck Surg. 2016 Feb;142(2): 162-7.
35 Han YY, Forno E, Gogna M, Celedón JC. Obesity and rhinitis in a nationwide study of children and adults in the United States. J Allergy Clin Immunol. 2016 May;137(5):1460-5.

36 Irei AV, Takahashi K, Le DS, Ha PT, Hung NT, Kunii D, et al. Obesity is associated with increased risk of allergy in Vietnamese adolescents. Eur J Clin Nutr. 2005 Apr;59(4):5717.

37 Visness CM, London SJ, Daniels JL, Kaufman JS, Yeatts KB, Siega-Riz AM, et al. Association of obesity with IgE levels and allergy symptoms in children and adolescents: results from the National Health and Nutrition Examination Survey 2005-2006. J Allergy Clin Immunol. 2009 May;123(5):1163-9. 1169.e1-4.
38 Lei Y, Yang H, Zhen L. Obesity is a risk factor for allergic rhinitis in children of Wuhan (China). Asia Pac Allergy. 2016 Apr;6(2): 101-4.

39 Sybilski AJ, Raciborski F, Lipiec A, Tomaszewska A, Lusawa A, Furmańczyk K, et al. Obesity: a risk factor for asthma, but not for atopic dermatitis, allergic rhinitis and sensitization. Public Health Nutr. 2015 Feb;18(3): 530-6.

40 Konno S, Hizawa N, Fukutomi Y, Taniguchi M, Kawagishi Y, Okada C, et al. The prevalence of rhinitis and its association with smoking and obesity in a nationwide survey of Japanese adults. Allergy. 2012 May;67(5): 653-60. 